\title{
Structural and functional characterization of a cold adapted stand-alone TPM domain reveals a relationship between dynamics and phosphatase activity
}

\author{
Leonardo Pellizza* ${ }^{1}$, Clara Smal*1, Raúl E. Ithuralde ${ }^{2}$, Adrián G. Turjanski ${ }^{2}$, Daniel O.
} Cicero $^{\ddagger 3}$, Martin Aran $\$ 1$

${ }^{1}$ Fundación Instituto Leloir, IIBBA-CONICET, Patricias Argentinas 435 (C1405BWE) Buenos Aires, Argentina

${ }^{2}$ Departamento de Química Biológica, Facultad de Ciencias Exactas y Naturales, Universidad de Buenos Aires, Intendente Güiraldes 2160 (C1428EGA) Argentina e IQUIBICEN-CONICET

${ }^{3}$ Dipartimento di Scienze e Tecnologie Chimiche, Università di Roma "Tor Vergata", via della Ricerca Scientifica SNC (00133) Rome, Italy

${ }^{*}$ Contributed equally to this work

\$Corresponding author: Martín Arán, Fundación Instituto Leloir, IIBBA-CONICET, Patricias Argentinas 435 (C1405BWE) Buenos Aires, Argentina, Phone: +54 011 52387500, e-mail: maran@leloir.org.ar.

Running title: Relationship between conformational dynamics and metaldependent phosphatase activity of a stand-alone TPM domain from Bizionia argentinensis

Article type : Original Article

Keywords: Structural genomics, Antarctic bacteria, Bizionia argentinensis, TPM domain, Phosphatase activity, Nuclear Magnetic Resonance

This article has been accepted for publication and undergone full peer review but has not been through the copyediting, typesetting, pagination and proofreading process, which may lead to differences between this version and the Version of Record. Please cite this article as doi: 10.1111/febs.13929

This article is protected by copyright. All rights reserved. 
Abbreviations: pNPP, p-Nitro phenyl phosphate; pSer, O-phospho-L-serine; CD, circular dichroism; EDTA, Ethylenediaminetetraacetic acid; NMR: Nuclear magnetic resonance; HSQC, Heteronuclear Single Quantum Coherence; NOE, Nuclear Overhauser Effect; MD, Molecular Dynamics; CSP, Chemical Shift Perturbation. RMSD, Root-Mean-Square deviation; RMSF, Root-Mean-Square Fluctuations;

Conflicts of interest: The authors declare that there is no conflict of interest regarding the publication of this paper

\section{ABSTRACT}

The TPM domain constitutes a family of recently characterized protein domains that are present in most living organisms. Although some progress has been made in understanding the cellular role of TPM-containing proteins, the relationship between structure and function it is not clear yet. We have recently solved the solution and crystal structure of one TPM domain (BA42) from the Antarctic bacterium Bizionia argentinensis. In this work we demonstrate that BA42 has phosphoric-monoester hydrolase activity. The activity of BA42 is strictly dependent on the binding of divalent metals and retains nearly $70 \%$ of the maximum at $4^{\circ} \mathrm{C}$, a typical characteristic of cold adapted enzymes. From HSQC, ${ }^{15} \mathrm{~N}$ relaxation measurements and molecular dynamics studies we determine that the flexibility of the crossing loops was associated to the protein activity. Thermal unfolding experiments showed that the local increment in flexibility of $\mathrm{Mg}^{2+}$-bound BA42, when compared with $\mathrm{Ca}^{2+}$-bound BA42, is associated to a decrease in global protein stability. Finally, through mutagenesis experiments we unambiguously demonstrate that the region comprising the metal binding site participates in the catalytic mechanism. The results shown here contribute to the 
understanding of the relationship between structure and function of this newly family of TPM domains providing important cues on the regulatory role of $\mathrm{Mg}^{2+}$ and $\mathrm{Ca}^{2+}$ and the molecular mechanism underlying enzyme activity at low temperatures.

\section{INTRODUCTION}

The TPM domains (Pfam PF04536) represent a super family of poorly characterized protein domains widely distributed in eukarya and eubacteria that have been implicated in diverse cellular processes such as photosynthesis and synaptic transmission $[1,2]$. The TPM domain family, previously referred to as "DUF477" and "Repair_PSII", has received its name from the first three proteins studied; TLP18.3, Psb32 and MOLO-1 [2, 3].

In recent years, the structure of four TPM domains present in several proteins have been determined (CG2496 from Corynebacterium glutamicum [PDB code 2KPT], PG0361 from Porphyromonas gingivalis [PDB code 2KW7], BA42 from Bizionia argentinensis [PDB codes 2MPB and 4OA3] [4] and AtTPL18.3 from Arabidopsis thaliana (PDB code 3PTJ) [2]). These structures, despite sharing a very low sequence identity (less than $15 \%$ ), present a similar $\alpha \beta \alpha$ "sandwich" conformation, not previously found in other protein domains. The function of CG2496, PG0361 and BA42 remains unknown, whereas AtTLP18.3 was classified as a thylakoid acid phosphatase [2], and was proposed to provide partial protection for the PSII complex to resist photoinhibition under fluctuating high-light conditions [5].

In addition to these four TPM family members with known structure, other TPMcontaining proteins have been functionally characterized so far. MOLO-1 was identified as a positive regulator of levamisole-sensitive acetylcholine receptors at the Caenorhabditis elegans neuromuscular junction [6]. The Psb32 protein from Synechosystis sp., similar to AtTLP18.3, protects photosystem II from photodamage and accelerates its repair. Very 
recently, a functional analysis of the TPM-containing protein Rv2345 from the pathogenic bacteria Mycobacterium tuberculosis [7] characterized its phosphatase and ATPase activities. Finally, it has been shown that the TPM domain of the CG2496 protein from Corynebacterium glutamicum interacts with methiothepin, a potential lead compound for antibiotics [8].

Although some progress has been made in understanding the cellular role of TPMcontaining proteins, it is not yet clear the relationship between structure and function of this family of domains. Indeed, there is only one TPM family member with known structure functionally characterized to date [2]

In this context, we have recently solved the solution and crystal structure of BA42, a protein from the Antarctic bacterium Bizionia argentinensis [4]. BA42 is the first structure of a member of the PF04536 family comprised of a stand-alone TPM domain. The structure reveals a new topological variant of the four $\beta$-strands constituting the central $\beta$-sheet of the $\alpha \beta \alpha$ architecture and a double metal binding site stabilizing a pair of crossing loops, not observed in previous structures of proteins belonging to this family. The metal-bound form of BA42 is characterized by a notable rigidity, with the exception of the first seven residues. Without the metal, BA42 undergoes a transition to a more flexible structure, presenting a long C-terminal tail of 17 residues largely disordered [4]. Furthermore, BA42 lacks both an Nterminal signal sequence and a transmembrane region, therefore, in contrast to the other characterized TPM family members, it is most probably localized in the cytoplasm.

In order to characterize the functional role of BA42 and based on the previously characterized TPM domains [2,7], we tested the possible phosphatase activity of this protein. Here we demonstrate that BA42 has in vitro phosphoric-monoester hydrolase activity (EC 3.1.3), similar to others TPM members. Further characterization indicated that the activity of BA42 is strictly dependent on the presence of divalent cations, being $\mathrm{Mg}^{2+}$ the most efficient 
to increase the enzyme activity. The protein retained nearly $70 \%$ of maximum activity at $4^{\circ}$ $\mathrm{C}$, a typical characteristic of cold adapted enzymes. From HSQC, ${ }^{15} \mathrm{~N}$ relaxation measurements and molecular dynamics simulations we determined that the binding of $\mathrm{Mg}^{2+}$ to BA42, when compared with $\mathrm{Ca}^{2+}$, induces local changes in the metal binding site and on residues of the crossing loops. Although the global structure of $\mathrm{Mg}^{2+}$-bound BA42 seemed to be similar to the $\mathrm{Ca}^{2+}$-bound BA42, an increased flexibility was observed in the region of the crossing loops indicating that changes in local flexibility are related to enzymatic activity, as observed for other cold-adapted enzymes $[9,10]$. Thermal unfolding experiments showed that the increased flexibility of $\mathrm{Mg}^{2+}$-bound BA42 correlates with a reduction of protein stability. Furthermore, the results obtained from mutagenesis experiments were in line with our previous results and allowed the identification of a region encompassing the metal binding site that participate in the catalytic reaction. These results characterize for the first time at atomic level the function of a TPM-containing protein and strongly support that this domain family has phosphatase activity. Moreover, the activity of BA42 is regulated by $\mathrm{Mg}^{2+}$ and $\mathrm{Ca}^{2+}$ and the increased flexibility of the crossing loops induced by $\mathrm{Mg}^{2+}$ emerged as an important feature that may explain the catalytic mechanism underlying enzymatic activity at low temperatures.

\section{RESULTS}

\section{Phosphoric hydrolase activity of BA42}

Previous studies showed that TPM domains of Rv2345 and AtTLP18.3 are capable of removing phosphate groups from different substrates $[2,7]$. Although the structure of the TPM domain of Rv2345 is currently unknown, a pairwise sequence alignment between this domain and the TPM domain of AtTLP18.3 [7] showed conserved regions of key residues 
proposed to be involved in substrate binding. In line with this, a pairwise sequence alignment between BA42 and AtTLP18.3 (15\% of sequence identity) showed conserved amino acids residues reported to be essential for substrate binding in the acid phosphatase of A. thaliana (Figure 1A). Val101, Asp102 and Lys112 have been shown to interact with the substrate in the crystalline structure of the AtTLP18.3-Ser complex [2]. The alignment showed the conservation of Val17 and Asp18 in the primary sequence of BA42. However, we were unable to find a conserved residue in BA42 corresponding to Lys112 in AtTLP18.3. In this respect it is worth mentioning that Lys 112 has been shown to be exclusively conserved in land plants [2].

These previous observations led us to the hypothesis that BA42 might also have a role as phosphoric-monoester hydrolase. However, despite this sequence conservation, a structural alignment between BA42 and AtTLP18.3 clearly showed that conserved residues are located in different secondary structure elements of the TPM fold (Figure 1C). Although the substrate binding residues in AtTLP18.3 are positioned at the $\beta$-sheet I, the conserved hypothetical substrate binding residues in BA42 are placed in $\alpha$-helix I. In this sense, the spatial arrangement of these residues in the structure of BA42 is significantly different to the spatial configuration observed in the substrate binding site of AtTLP18.3. In consequence, this feature hinders the possibility that both domains could share the same substrate binding site. Moreover, as mentioned before, BA42 has a distinctive folding topology that introduces a remarkable conformational difference in the region encompassing the substrate and the metal binding sites in the structure of AtTLP18.3 (Figure 1C) [4]. In this regard, from a detailed inspection of the proteins classified in the PF04536 family we noted that most members (polypeptides with a size ranging between 270 to 290 amino acids) have a similar topology characterized by the presence of an N-terminal signal sequence followed by the TPM domain, a transmembrane domain, and a C-terminal low complexity region with variable length. This 
group includes AtTLP18.3, and other TPM-containing proteins characterized so far. In contrast, as mentioned above, BA42 is a stand-alone TPM domain with a distinctive topology and predicted to be cytoplasmic. Relevant to these observations, from a sequence similarity search using the BLASTp program we detected that proteins homologous to BA42 (i.e. standalone TPM domains) are almost exclusively conserved within the phylum Bacteroidetes. Interesting, a multiple alignment of homologous BA42 sequences showed no strict conservation of the VDK triad corresponding to the substrate binding site in AtTLP18.3 (Figure 1B). However, a remarkable conservation was observed for residues involved in the metal binding site, the down crossing loop and the $\beta$-sheet I in BA42 (Figure 1B).

Despite the fact that BA42 may lack an active site homologous to AtTLP18.3, the hypothesis that BA42 might acts as a phosphoric hydrolase could not be ruled out. First, similar to AtTLP18.3, BA42 contains metals in its structure, being a characteristic feature of other phosphoric-monoester hydrolases $[11,12]$. Second, BA42 belongs to a psychrophilic organism and therefore may have evolved an alternative active site with dynamics and structural characteristics suitable for cold catalysis. Finally, through a structural comparison with DALI [13] and MATRAS [14] programs, we found that BA42 shared high structural similarity with hydrolases, as previously observed for AtTLP18.3 [2].

In this context, we analyzed the phosphoric-monoester hydrolase activity (hereafter referred to as phosphatase) of BA42 by use of the general substrates p-nitrophenyl phosphate (pNPP) and phosphoserine (pSer) at $25{ }^{\circ} \mathrm{C}$. Initial results indicated that BA42 contained phosphatase activity (Figure 2A). In these assays we used the TEV protease as a control [15], a protein lacking phosphatase activity. BA42 showed enzymatic activity with both substrates, while being more efficient to hydrolyze the pSer. Interestingly, the enzymatic activity of BA42 was dramatically inhibited after pretreatment with EDTA. Consequently, to characterize the effect of bivalent metals on the phosphatase activity we performed the assay

This article is protected by copyright. All rights reserved. 
with the metal-free BA42 in the presence of several divalent ions $\left(\mathrm{Mg}^{2+}, \mathrm{Ca}^{2+}, \mathrm{Mn}^{2+}\right.$ and $\mathrm{Zn}^{2+}$ ) using pSer as substrate (Figure 2B). When incubated with $\mathrm{Mg}^{2+}$ the activity of BA42 was significantly increased (up to five-fold) in comparison to the other divalent metal ions assayed.

We determined the optimal enzymatic conditions of $\mathrm{Mg}^{2+}$-bound BA42 for pSer. The highest activity was observed at $\mathrm{pH} 7.0$ and around $20-22^{\circ} \mathrm{C}$ (Figure $3 \mathrm{~A}$ and $3 \mathrm{~B}$ ). Of note, as observed for psychrophilic enzymes [16], the protein retained nearly $70 \%$ of maximum activity at $4^{\circ} \mathrm{C}$. Kinetics assay of BA42 were performed for pSer and the results were best fitted to an allosteric sigmoidal (Figure 3C). The apparent substrate-binding activity affinity $(\mathrm{Km})$ was $5.63 \pm 1.82 \mathrm{mM}$, the catalytic velocity (Vmax) was $3.95 \pm 1.26 \mathrm{nmol} \mathrm{min}^{-1} \mathrm{mg}^{-1}$ and the kcat was $0.067 \pm 0.002 \mathrm{~min}^{-1}$ at the optimal condition of $20-22{ }^{\circ} \mathrm{C}$ and $\mathrm{pH} 7.0$.

\section{The binding of $\mathrm{Mg}^{2+}$ to $\mathrm{BA42}$ is associated with an increase in enzyme activity}

We have previously showed that it is possible to follow conformational changes associated to $\mathrm{Ca}^{2+}$ binding of metal-free BA42 by inspection of resonances in the range of 0.5 to $-1.5 \mathrm{ppm}$ in the $1 \mathrm{D}{ }^{1} \mathrm{H}$ NMR spectrum [4]. Accordingly, we used the same procedure to monitor conformational changes of metal-free BA42 upon binding of other bivalent metals (Figure 4A). All different metals tested were able to bind BA42 and displayed a similar behavior of the $1 \mathrm{D}{ }^{1} \mathrm{H}$ NMR spectrum as previously observed for $\mathrm{Ca}^{2+}$. Hence, we hypothesized that binding of divalent metals results in a global conformational change similar

to that reported for $\mathrm{Ca}^{2+}$. Surprisingly, unlike the other cations tested, $\mathrm{Mg}^{2+}$ presented a differential behavior. The dissociation constant for this bivalent ion was $87 \mu \mathrm{M}$ whereas the other metals showed dissociation constants of $48 \mu \mathrm{M}$ in average. But most important, the maximum activity in the presence of $\mathrm{Mg}^{2+}$ was on average five-fold greater than with $\mathrm{Ca}^{2+}$, 
$\mathrm{Mn}^{2+}$ or $\mathrm{Zn}^{2+}$ (Figure 4B). The observed behavior when the enzyme was titrated with $\mathrm{Mg}^{2+}$ was better appreciated by plotting the activity and the conformational change together in the same graph (Figure 4C). It was very clear that the binding of $\mathrm{Mg}^{2+}$, followed by monitoring the conformational change from metal-free to $\mathrm{Mg}^{2+}$-bound $\mathrm{BA} 42$, was associated with an increase in enzyme activity. In this regard, it is interesting to note that even though all bivalent metals tested were able to induce the conformational change of the metal-free BA42, $\mathrm{Mg}^{2+}$ was the most efficient in increasing the enzymatic activity. This suggests a strict specificity in the type of metal in the catalytic mechanism.

\section{$\mathrm{Mg}^{2+}$-bound BA42 exhibits local conformational changes with respect to $\mathrm{Ca}^{2+}$-bound}

\section{BA42}

We recently proved that $\mathrm{Ca}^{2+}$ binding is crucial for stabilization of the BA42 structure, involving the closure of the C-terminal segment anchored to the $\alpha \beta \alpha$ region, generating a rigid conformation [4]. To investigate whether $\mathrm{Mg}^{2+}$ induced the same conformational change, we analyzed the ${ }^{1} \mathrm{H}_{-}{ }^{15} \mathrm{~N}$ HSQC spectra of metal-bound BA42 with $\mathrm{Ca}^{2+}$ and $\mathrm{Mg}^{2+}$ (Figure 5). Interestingly, although both spectra showed a similar pattern of cross-peaks with minor variations, a group of cross-peaks in the $\mathrm{Mg}^{2+}$-bound BA42 HSQC spectrum could not be detected (Figure 5). This was the case of amide signals of residues 21, 26, 28, 31, adjacent to the metal binding site, and residues 131-137, comprising the up crossing loop in the $\mathrm{Ca}^{2+}$ bound BA42 (Figure 5). The disappearance of these signals could be attributed to: i) an increased flexibility associated to slow or intermediate conformational motions, ii) a higher solvent exposition or iii) Large chemical shift differences in the $\mathrm{Ca}^{2+}$ and $\mathrm{Mg}^{2+}$-bound states that make it difficult to match the corresponding resonances, hence the apparent disappearance. However, no resonances in the $\mathrm{Mg}^{2+}$-bound state could be assigned to the 
missing resonances, ruling out this option. Furthermore, we were unable to detect the appearance of these amide signals in HSQC spectra performed at low $\mathrm{pH}$ (up to the limit of precipitation of the protein), thus discarding the disappearance of the signals due to a greater exchange with the solvent. Therefore, we hypothesized that binding of $\mathrm{Mg}^{2+}$ destabilizes the conformation of the crossing loops.

To further analyze the differences between $\mathrm{Mg}^{2+}$-bound and $\mathrm{Ca}^{2+}$-bound BA42 HSQCs, we performed a chemical shift perturbation (CSP) study (Figure 6A). We found major changes in the amide signals of residues that directly interact with the metals and others close to the binding site, specifically in the down crossing loop and the loop that connects the $\beta$ sheet B with the $\alpha$-helix II (Figure 6E and 6F). Residues 22, 24, 25, 27, 30, 59, 60, 61 and 140 showed CSP values above the threshold line.

Taken together, these results clearly indicated that the binding of $\mathrm{Mg}^{2+}$ to BA42 (in place of $\mathrm{Ca}^{2+}$ ) induced local changes in the metal binding site and residues of the crossing loops. Although the global structure of $\mathrm{Mg}^{2+}$-bound BA42 seemed to be similar to the $\mathrm{Ca}^{2+}$-bound BA42, the increased flexibility of the crossing loops induced by $\mathrm{Mg}^{2+}$ emerged as an important feature that may probably explain the enhancement of the phosphatase activity.

\section{$\mathrm{Mg}^{2+}$-bound BA42 presents an increment of slow internal motions in the down crossing loop and the C-terminal region}

To study the effect of $\mathrm{Mg}^{2+}$ on the overall backbone dynamics of BA42 at a residue level, we performed ${ }^{15} \mathrm{~N}$ relaxation measurements on ${ }^{15} \mathrm{~N}$ - metal-bound-BA42 with $\mathrm{Ca}^{2+}$ and $\mathrm{Mg}^{2+}$. As reported previously [4], $\mathrm{Ca}^{2+}$-bound $\mathrm{BA} 42$ exhibits rather uniform values of relaxation rates along the protein sequence, a sign of a compact globular monomeric protein. Indeed, the average $T_{1} / T_{2}$ value is $8.0 \pm 0.2 \mathrm{~ns}$ at $28^{\circ} \mathrm{C}$. The $\mathrm{Mg}^{2+}$-bound $\mathrm{BA} 42 T_{1} / T_{2}$ ratios were very 
similar to those $\mathrm{Ca}^{2+}$-bound BA42, including anisotropic tumbling effects as a result of the shape of the molecule [4] (Figure 6B). However, some residues in $\mathrm{Mg}^{2+}$-bound BA42 displayed relative high $T_{1} / T_{2}$ ratios and a shorter $T_{2}$. They were those in the D22-E30 region, comprising the down crossing loop, and N140-K144, belonging to the C-terminal region, suggesting the presence of low-frequency motions ( $\mu \mathrm{s}-\mathrm{ms})$, timescales often associated with conformational exchange. In addition, the loop that connects the $\beta$-sheet B with the $\alpha$-helix II, that displayed significant variations in the CSP experiment, showed minor changes in dynamics between $\mathrm{Mg}^{2+}$-bound and $\mathrm{Ca}^{2+}$-bound BA42.

On the other hand, the hnNOE values obtained for $\mathrm{Mg}^{2+}$-bound BA42 were almost identical to the values obtained for $\mathrm{Ca}^{2+}$-bound $\mathrm{BA} 42$, thus indicating that no new fast internal motions (ps-ns) appeared in the protein bound to $\mathrm{Mg}^{2+}$ (Figure 6C). Therefore, in line with our previous results, the backbone dynamics experiments clearly indicated that $\mathrm{Mg}^{2+}$ bound BA42, when compared with $\mathrm{Ca}^{2+}$-bound BA42, presented increased flexibility (in the slow timescale, $\mu \mathrm{s}-\mathrm{ms}$ ) in the region comprising the down crossing loop and the C-terminal region.

Additionally, to further studying differences in the dynamics of BA42 with $\mathrm{Ca}^{2+}$ and $\mathrm{Mg}^{2+}$, we performed all-atom Molecular Dynamics (MD) in explicit solvent and in the presence of one of the two ions in both coordination sites. MD simulations were converged, as shown by RMSD vs time plots (Figure 6G). When analyzing fluctuations by residue, we observed a significant increase in the C-terminal region of the $\mathrm{Mg}^{2+}$-bound $\mathrm{BA} 42$, as can be seen in the RMSF plot (Figure 6D), and in agreement with our previous NMR experiments.

This article is protected by copyright. All rights reserved. 


\section{$\mathrm{Mg}^{2+}$-bound BA42 displays changes in thermal stability with respect to $\mathrm{Ca}^{2+}$-bound and metal-free BA42}

We have previously shown the strong difference in the conformational stability between metal-free and $\mathrm{Ca}^{2+}$-bound BA42 [4]. In order to assess whether the conformational change induced by the binding of $\mathrm{Mg}^{2+}$ affected the stability of the protein, we carried out thermal denaturation experiments followed by circular dichroism (CD). In a first experiment, we found that the far-UV spectra of $\mathrm{Ca}^{2+}$-bound and $\mathrm{Mg}^{2+}$-bound BA42 were almost identical to each other, but slightly different to the spectrum of EDTA-treated (metal-free) BA42. The three spectra were dominated by an $\alpha$-helix content with two minima at $209 \mathrm{~nm}$ and $223 \mathrm{~nm}$ (Figure 7A). We next investigated the thermal unfolding of metal-free, $\mathrm{Ca}^{2+}$-bound and $\mathrm{Mg}^{2+}$ bound BA42 by recording the molar ellipticity at $222 \mathrm{~nm}$ at different temperatures (Figure 7B). All the three variants tested showed a reversible unfolding-folding process and displayed a cooperative behavior in the thermal denaturation process. However, $\mathrm{Ca}^{2+}$-bound $\mathrm{BA} 42$ turned out to be more stable than $\mathrm{Mg}^{2+}$-bound BA42 and the later more stable than metal-free BA42, being the calculated $\mathrm{Tm} 61.3 \pm 0.2{ }^{\circ} \mathrm{C}, 57.0 \pm 0.2{ }^{\circ} \mathrm{C}$ and $47.9 \pm 0.3{ }^{\circ} \mathrm{C}$, respectively (Figure 7B).

\section{BA42 mutants unable to bind $\mathrm{Mg}^{2+}$ reveal the location of the active site}

As mentioned above, the crystalline structure of the AtTLP18.3-Ser complex [2] revealed a VDK triad shown to constitute the substrate binding site. Moreover, a calcium ion binding site stabilized by six hydrogen bonds was also suggested to be involved in AtTLP18.3 phosphatase activity. In contrast, the VDK triad it is clearly not present in the structure of BA42 (Figure 1B and 1C) and two calcium ions are bound on the other side of the molecule (i.e. shifted $20 \AA$ of the corresponding metal binding site in AtTLP18.3). At this point, based 
on our experiments we could not exclude the coexistence of two metal binding sites in BA42: one structural identified in the BA42 crystal structure and one catalytic as proposed in AtTLP18.3. If structural sites had higher affinity than the catalytic site it would be difficult to identify the two sites from titrations. Therefore, in order to evaluate these possibilities we conducted mutagenesis experiments. First, we generated a BA42 variant comprised of residues 1-130 (BA42- $\Delta \mathrm{CT})$. BA42- $\Delta \mathrm{CT}$ lacks the $\mathrm{C}$-terminal region where most of the residues constituting the metal binding site are located (Figure 8A and 8B). Interesting, no activity in the presence of $\mathrm{Mg}^{2+}$ was detected for BA42- $\Delta \mathrm{CT}$ as compared with the wild-type protein (Figure 8D), thus ruling out the presence of a catalytic site in BA42 in a region different from that constituted by the metal binding site. In addition, in contrast to the wildtype protein where the structural change in the presence of $\mathrm{Mg}^{2+}$ was clearly evident, $1 \mathrm{D}{ }^{1} \mathrm{H}$ NMR spectra of BA42- $\Delta \mathrm{CT}$ were virtually unchanged in the presence of the divalent ion (Figure 8C).

However, although the results obtained with BA42- $\Delta \mathrm{CT}$ clearly demonstrate the absence of a catalytic site outside the metal binding site in BA42, the generation of this mutant involves the removal of a large number of amino acids which can lead to a subtle conformational change that may indirectly affect the potential active site. Therefore, we considered that to better evaluate the enzyme activity of BA42 it would be more appropriate to produce a protein variant with fewer mutated residues which, similar to BA42- $\Delta \mathrm{CT}$, had the characteristic of not binding $\mathrm{Mg}^{2+}$. In this respect, we generated BA42 variants carrying single-point mutations in residues involved in the metal binding site. We found that the single-point mutation of Glutamic acid 30 to Alanine (BA42-E30A) generated a protein which lacked the ability to bind $\mathrm{Mg}^{2+}$ (Figure 8C). It is interesting to note that Glutamic 30 has the particularity of interacting with the two metals ions in the structure of BA42 (Figure 8B) and is highly conserved among stand-alone TPM proteins (Figure 1B). In line with the 
behavior observed for BA42- $\Delta \mathrm{CT}$, the mutant BA42-E30A showed no significant differences between the $1 \mathrm{D}{ }^{1} \mathrm{H}$ NMR spectra of the metal-free protein and in the presence of $\mathrm{Mg}^{2+}$ (Figure 8C). But most importantly, BA42-E30A did not show phosphatase activity (Figure 8D). This observation was congruent with the previous results with BA42- $\Delta \mathrm{CT}$, but in this case the loss of activity was associated to a single-point mutation of a residue specifically involved in the metal binding site of BA42, discarding any artifact due to the removal of a large number of amino acids.

As a control, CD spectra of the BA42-E30A and BA42- $\Delta$ CT were found to be practically identical to the spectrum of the metal-free wild-type protein (Figure 8E), thus indicating the integrity of the secondary structure and the absence of large conformational changes of mutant proteins with respect to the metal-free wild-type BA42.

\section{DISCUSSION}

BA42 is the first member of the PF04536 family comprised of a stand-alone TPM domain structurally and biochemically characterized to date. The structure of BA42 uncovers a new topological variant of the four $\beta$-strands constituting the central $\beta$-sheet of the $\alpha \beta \alpha$ architecture and a double metal binding site stabilizing a pair of crossing loops, not observed in previous structures of proteins belonging to this family. Furthermore, in contrast to other characterized TPM family members, BA42 has predicted cytoplasmic localization.

Previously, another structural characterized TPM-containing protein, AtTPL18.3, was reported to have phosphatase activity [2]. Here we show that beside the fact that BA42 has the conserved residues involved in the catalytic mechanism, they do not have a spatial arrangement compatible with the active site reported for AtTPL18.3 [2]. Despite this 
discrepancy in the structure of the potential active site, in this work we demonstrate that BA42 has phosphatase activity and displays characteristics compatible with psychrophilic enzymes [16] presenting a maximum activity at $20-22^{\circ} \mathrm{C}$. In this sense, it is worth to mention that the most favorable growth condition of Bizionia argentinensis it is around $22-25{ }^{\circ} \mathrm{C}$, which is surprisingly similar to the optimal catalytic temperature reported here for BA42. Although the absolute values of activity are low compared with other hydrolases enzymes [17], they are in line with those reported previously for other members of the TPM family [2, 7]. Furthermore, since the physiological substrate of BA42 is not known, the low activity observed in vitro may also be attributed to suboptimal reaction conditions.

In the present study, we show the strict dependence of the activity of BA42 on the presence of divalent ions. Although the protein presents no activity when pretreated with EDTA, activity is observed after treatment with different metallic cationic ions. Interestingly, an increase of about five fold is observed in the presence of $\mathrm{Mg}^{2+}$ in comparison with other metals tested. This increase in the enzyme activity is associated to a conformational change of BA42 from a structure with an unfolded C-terminal region to a closed structure with the Cterminal tail bound to the protein core. However, all metals tested induce a similar conformational change in BA42 and even with higher affinity than $\mathrm{Mg}^{2+}$. The major differences in the conformation of $\mathrm{Mg}^{2+}$-bound BA42 reside in the dynamics of the crossing loops and the metal binding site. Two independent experiments denote an increase in the flexibility of these regions. First, the HSQC spectra of the $\mathrm{Mg}^{2+}$-bound protein reveal the disappearance of amide signals of residues adjacent to the cation binding site and residues 131-137, comprising the up crossing loop in the $\mathrm{Ca}^{2+}$-bound $\mathrm{BA} 42$, which presented a defined conformation. Since neither a large chemical shift variation nor an increase in solvent exposure was detected in this region, we conclude that this is due to a gain in flexibility (in the scale of slow or intermediate movements, $\mu \mathrm{s}-\mathrm{ms})$. Second, ${ }^{15} \mathrm{~N}$ relaxation experiments 
clearly show an increase in slow movements ( $\mu \mathrm{s}-\mathrm{ms}$ ) of residues D22-E30, comprising the down crossing loop, and N140-K144, belonging to the C-terminal portion. Furthermore, the lower conformational stability of $\mathrm{Mg}^{2+}$-bound $\mathrm{BA} 42$ with respect to $\mathrm{Ca}^{2+}$-bound $\mathrm{BA} 42$, detected in thermal denaturation experiments, could be attributed to an increase in the flexibility of this region. In line with this, MD simulations provide further evidence of increased flexibility in residues belonging to the C-terminal portion.

Taken together, these results indicate that binding of $\mathrm{Mg}^{2+}$ to BA42 induces local flexibility in the region comprising the crossing loops and residues involved in metal binding. This characteristic is associated with a decrease in the global conformational stability and an improvement of the catalytic activity, compared with $\mathrm{Ca}^{2+}$-bound BA42.

In order to further evaluate the relationship between the flexibility and the catalytic activity, we compared the enzyme activity between $\mathrm{Ca}^{2+}$-bound and $\mathrm{Mg}^{2+}$-bound BA42 as a function of temperature (Figure 7C). Although the activity of $\mathrm{Ca}^{2+}$-bound BA42 was lower than $\mathrm{Mg}^{2+}$-bound BA42 over the whole temperature range studied, major differences were detected below $26^{\circ} \mathrm{C}$. Interestingly, the maximum activity of $\mathrm{Ca}^{2+}$-bound BA42 was found at $37^{\circ} \mathrm{C}$, shifted about $17^{\circ} \mathrm{C}$ relative to that observed for the $\mathrm{Mg}^{2+}$-bound BA42 (around 20-22 $\left.{ }^{\circ} \mathrm{C}\right)$. In consequence, these results were compatible with the idea that the presence of a flexible active site in BA42 generates a more efficient enzyme to catalyze at low temperatures.

In response to low temperatures, psychrophiles use diverse strategies for adaptation [18, 19]. In most organism the flexibility of the structural elements that are involved in the catalytic cycle of enzymes are commonly adjusted, resulting in a loose structure characterized by a low local conformational stability and/or by destabilization of the whole molecule $[9$, 20]. This involves a reduction in the number and strength of all types of weak interactions or the disappearance of stability factors, resulting in improved dynamics of active site residues 
in the cold. In this scenario, based on our results, we can hypothesize that the region comprising the crossing loops and residues involved in metal binding in BA42 is directly related to the catalytic mechanism and may contain the active site. Furthermore, it has been observed in several enzymes that "crossing loops" structures are part of the active site [21, 22]. In this respect, the results obtained with BA42- $\Delta \mathrm{CT}$ and BA42-E30A were crucial to circumscribe the active site of BA42 in a region constituted by the metals binding site and to rule out the existence of an active site similar to the reported for AtTLP18.3 [2]. At this point, given the differences observed between BA42 and AtTLP18.3 regarding the folding topology, the metal binding site and the location of the active site we propose that to study TPM-containing proteins more appropriately, they might be classified in at least two groups: membrane-associated TPMs and cytoplasmic stand-alone TPMs. Cytoplasmic stand-alone TPMs seem to be almost exclusively conserved within the phylum Bacteroidetes, while membrane-associated TPMs appear to be conserved over a wide range of organisms (including plants, fungi and bacteria). In particular, since both groups of TPM-containing proteins are found in Bacteroidetes, we hypothesize that these domains have evolved independently. In addition, cytoplasmic stand-alone TPMs are mainly found in marine organisms adapted to low temperatures and, therefore, we assume that the members of this group conserve structural features compatible with the activity at these environmental conditions, similar to those described for BA42.

On this bases, we hypothesize that BA42 might evolved a catalytic site where activity at low temperature is regulated, at least in part, by varying the flexibility of the active site. In the presence of $\mathrm{Ca}^{2+}$ the active site becomes rigid and the activity is depressed, whereas the binding of $\mathrm{Mg}^{2+}$ enhances the flexibility in a way compatible with catalysis at low temperatures (Figure 9). In this sense, $\mathrm{Mg}^{2+}$ is the most abundant divalent metal in living cells. It has been reported that the intracellular levels of $\mathrm{Mg}^{2+}$ in marine bacteria may vary 
from 130 to $710 \mathrm{mM}$ in normal growth conditions [23] and even up to $910 \mathrm{mM}$ under carbon limitation or dormancy [24]. In addition, the intracellular $\mathrm{Ca}^{2+}$ concentration in these organisms ranges from 10 to $80 \mathrm{mM}$ [23]. Therefore, given the high concentration of these two metals, it can be predicted that BA42 may be found in the cytoplasm as metal-bound protein and the relative levels of $\mathrm{Ca}^{2+}$ and $\mathrm{Mg}^{2+}$ could be an important factor to modulate the phosphatase activity.

In conclusion, the results shown here contribute to the understanding of the relationship between structure and function of this recently characterized family of TPM domains. Our work, in conjunction with other previously described to date, suggest that the phosphoric hydrolase activity of the TPM scaffold has been conserved throughout evolution. However, more research is needed to uncover the catalytic and regulatory mechanisms relevant to its cellular function.

\section{MATERIALS AND METHODS}

\section{Construction of BA42 mutants}

BA42- $\Delta$ CT gene was amplified by PCR using Bizionia argentinensis genomic DNA as template, 5'-ATGTCTAAAATAGAAGAGTTTTTAAC-3' (primer A) as 5'-primer and 5'CCATGGAAAATATTTTGCCAAAGC-3' as $3^{\prime}$-primer. BA42-E30A site-directed mutant was generated by the megaprimer method using Bizionia argentinensis genomic DNA as template. The megaprimer was synthesized in a first PCR reaction using primer A as 5'-primer and 5'GAACACGTATGGCGCCAGACGTG-3’ as Mutagenic primer. The second PCR reaction was performed using the megaprimer as 5'-primer and 5'-TCCTTTTGAAATTGTGTTTGG-3' as 3'- 
primer. The final PCR products were purified and cloned between NdeI and BamHI restriction sites of the pET-28a(+) vector (Qiagen). Recombinant proteins contain a TEV protease cleavage site followed by $6 x$ Histidine tag for affinity purification. The quality of the preparations was analyzed by DNA sequencing. Finally, the recombined expression plasmids were transformed in Escherichia coli BL21 (DE3) competent cells (Stratagene, La Jolla, CA).

\section{Protein expression and purification}

BA42 recombinant proteins were expressed and purified as previously described [4].

\section{Phosphoric-monoester hydrolase activity}

The phosphoric-monoester hydrolase activity of BA42 was assayed by using of p-nitrophenylphosphate (pNPP) (New England Biolabs) and O-phosphoserine (pSer) (SigmaAldrich) as substrates. The reaction solution contained $15 \mu \mathrm{g}$ of purified BA42, $25 \mathrm{mM}$ HEPES ( $\mathrm{pH} 7$ ), and the substrates in a total volume of $0.1 \mathrm{~mL}$. The reactions were initiated by the addition of $20 \mathrm{mM}$ pNPP or pSer, and quenched by the addition of $10 \mu \mathrm{L}$ of $1 \mathrm{M}$ $\mathrm{NaOH}$. When pNPP was used as a substrate, the activity was measured by monitoring the change in the absorbance at $405 \mathrm{~nm}\left(\varepsilon 405 \mathrm{~nm}=18,300 \mathrm{M}^{-1} \mathrm{~cm}^{-1}\right)$ as pNPP (colorless) is converted to p-nitrophenol (pNP, yellow). For pSer, the method of Eibl and Lands [25] was used to detect the Pi released. All the assays were performed in triplicate. Enzymatic kinetics was analyzed by fitting the data to the allosteric sigmoidal equation using the nonlinear regression equation $\mathrm{Vi}=\left(\operatorname{Vmax} \cdot[\mathrm{S}]^{\mathrm{h}}\right) /\left(\mathrm{Km}_{\text {app }}+[\mathrm{S}]^{\mathrm{h}}\right)$, where Vi is the initial velocity, $[\mathrm{S}]$ is the concentration of the substrate and $\mathrm{h}$ is the Hill slope.

This article is protected by copyright. All rights reserved. 
In order to analyze the effect of divalent metal ions on the phosphoric-monoester hydrolase activity of BA42, the protein was treated with $1 \mathrm{mM}$ EDTA for 10 min and then extensively dialyzed against $25 \mathrm{mM}$ HEPES ( $\mathrm{pH}$ 7.0). After this treatment and before starting the enzymatic reaction, the enzyme was incubated with $1 \mathrm{mM} \mathrm{CaCl}_{2}, 1 \mathrm{mM} \mathrm{MgCl} 2,1 \mathrm{mM}$ $\mathrm{MnCl}_{2}$ or $1 \mathrm{mM} \mathrm{ZnCl}$ in the reaction buffer at $22^{\circ} \mathrm{C}$ for $10 \mathrm{~min}$, as indicated. The optimal reaction conditions for BA42 were determined using $\mathrm{pSer}$ as substrate. The optimal $\mathrm{pH}$ was determined by using $25 \mathrm{mM}$ acetic-acetate buffer (pH 5 to 7), $25 \mathrm{mM}$ Tris- $\mathrm{HCl}$ buffer (pH 7 to 9 ), and $25 \mathrm{mM}$ glycine- $\mathrm{NaOH}$ buffer (pH 9 to 12 ).

\section{Circular Dichroism (CD) measurements}

CD measurements were made on a Jasco J-815 spectropolarimeter (Jasco Inc., Easton, MD, USA). Circular dichroism spectra of BA42 were obtained in the range of 185-250 nm using a $0.2 \mathrm{~mm}$ path length and expressed in molar ellipticity $(\Theta)\left(\mathrm{deg} . \mathrm{cm}^{2} \cdot \mathrm{dmol}^{-1}\right)$. All measurements were carried out at a protein concentration of $2 \mu \mathrm{M}$ in $20 \mathrm{mM}$ HEPES pH 7.0.

Unfolding transitions as a function of temperature were monitored at $222 \mathrm{~nm}$. Temperature was varied from 25 to $75{ }^{\circ} \mathrm{C}$ at a constant rate of $1{ }^{\circ} \mathrm{C} . \mathrm{min}^{-1}$ and sampling at intervals of $1{ }^{\circ} \mathrm{C}$.

\section{NMR spectroscopy}

\section{NMR samples, data acquisition and processing}

Samples for NMR experiments contained $0.3-0.8 \mathrm{mM}{ }^{15} \mathrm{~N}$-labelled BA42 or $0.05-0.1$ $\mathrm{mM}$ unlabeled BA42 dissolved in a buffer containing $25 \mathrm{mM} \mathrm{NaCl}, 20 \mathrm{mM}$ HEPES and 5\% $\mathrm{D}_{2} \mathrm{O}, \mathrm{pH}$ 7. NMR experiments were performed at $298 \mathrm{~K}$ in a Bruker $600 \mathrm{MHz}$ Avance III 
spectrometer (Bruker Instruments, Inc., Bellerica, MA, USA) equipped with a 5-mm triple resonance cryoprobe incorporating shielded z-axis gradient coils. The NMR data were processed using NMRPIPE [26] and analyzed using NMRVIEWJ [27].

\section{${ }^{1}$ D NMR measurements}

The 1-1 Jump-and-return water suppression pulse sequence was used for ${ }^{1} \mathrm{H}$ 1D NMR experiments. In order to follow the conformational change of BA42 in the presence of divalent metals we measured the peak integral of methyl groups of residues I100 and V88, as reported previously [4].

\section{${ }^{15} \mathrm{~N}$ spin relaxation measurements}

Measurements of ${ }^{15} \mathrm{~N}$ T1, T2 and steady-state ${ }^{1} \mathrm{H}_{-}{ }^{15} \mathrm{~N}$ NOE (hnNOE) of BA42 was performed at a nitrogen frequency of $60.82 \mathrm{MHz}$ and $298 \mathrm{~K}$, using standard pulse schemes in an interleaved manner. Both $\mathrm{T} 1$ and $\mathrm{T} 2$ data were acquired with six relaxation delays. The delays used were 7, 300, 600, 900, 1200 and $1600 \mathrm{~ms}$ for the T1 calculations and 15.7, 31.4, $62.8,125.5,156.9$ and $219.7 \mathrm{~ms}$ for the $\mathrm{T} 2$ calculations. The rate analysis routine of NMRVIEWJ was used to analyze the data [27]. The hnNOE values were determined by the ratio of peak volumes of spectra recorded with and without ${ }^{1} \mathrm{H}$ saturation, employing a net relaxation delay of $4 \mathrm{~s}$ for each scan in both experiments. Typically, errors were $\sim 1 \%$ for $\mathrm{T} 1$ and $\mathrm{T} 2$ and $2-5 \%$ for hnNOE measurements.

\section{Molecular dynamics}

The initial structure files were obtained from the structure of BA42 from the Protein Data Bank (PDB ID: 4OA3) [4]. The AMBER99SB force field was used [28] and tleap program was used to create the topology and coordinate files. Amber was used for all molecular 
dynamics simulations [29]. Water molecules for explicit solvent conditions were represented using the TIP3P model [30]. The system was equilibrated in the NVT ensemble by running a 25 ps long MD simulation using the Berendsen thermostat [31] and then the temperature was slowly raised to $300 \mathrm{~K}$ while running another $25 \mathrm{ps}$ long simulation. During these processes the CA atoms were restrained using a harmonic potential with a $20 \mathrm{kcal} / \mathrm{mol}$ constant for the thermalization. This was followed by an equilibration process of $50 \mathrm{ps}$ with a 1 fs time step using Berendsen temperature with a coupling constant of 0.1 ps for keeping temperature constant at $300 \mathrm{~K}$ and Berendsen barostat for keeping pressure constant at $1 \mathrm{~atm}$ [31]. During $200 \mathrm{~ns}$ long production runs, the temperature was kept constant by the Berendsen thermostat algorithm set at $300 \mathrm{~K}$ with a $0.1 \mathrm{ps}$ coupling constant and pressure was kept constant at 1 atm by the Brendsen barostat [31]. The SHAKE algorithm was used for constraining the bonds that contained an $\mathrm{H}$ atom [32] and electrostatic interactions were calculated by the Particle Mesh Ewald decomposition algorithm [33]. A 2 fs time step was used. VMD program was used for visualization and RMSD and RMSF calculations [34].

\section{ACKNOWLEDGEMENTS}

This work was supported by the Consejo Nacional de Investigaciones Científicas y Técnicas (CONICET) and the Agencia Nacional de Promoción Científica y Tecnológica (ANPCyT).

\section{AUTHOR'S CONTRIBUTION}

LP and CS equally contributed to this work. LP, CS, REI and MA: Planned experiments, performed experiments, analyzed data and wrote the paper. AGT and DOC: Analyze data and wrote the paper.

This article is protected by copyright. All rights reserved. 


\section{REFERENCES}

1. Wegener KM, Bennewitz S, Oelmuller R \& Pakrasi HB (2011) The Psb32 protein aids in repairing photodamaged photosystem II in the cyanobacterium Synechocystis 6803. Mol Plant 4, 1052-1061.

2. Wu HY, Liu MS, Lin TP \& Cheng YS (2011) Structural and functional assays of AtTLP18.3 identify its novel acid phosphatase activity in thylakoid lumen. Plant Physiol 157, $1015-1025$

3. Eletsky A, Acton TB, Xiao R, Everett JK, Montelione GT \& Szyperski T (2012) Solution NMR structures reveal a distinct architecture and provide first structures for protein domain family PF04536. J Struct Funct Genomics 13, 9-14.

4. Aran M, Smal C, Pellizza L, Gallo M, Otero LH, Klinke S, Goldbaum FA, Ithurralde ER, Bercovich A, Mac Cormack WP, et al. (2014) Solution and crystal structure of BA42, a protein from the Antarctic bacterium Bizionia argentinensis comprised of a stand-alone TPM domain. Proteins 82, 3062-3078.

5. Sirpio S, Allahverdiyeva Y, Suorsa M, Paakkarinen V, Vainonen J, Battchikova N \& Aro EM (2007) TLP18.3, a novel thylakoid lumen protein regulating photosystem II repair cycle. Biochem J 406, 415-425.

6. Boulin T, Rapti G, Briseno-Roa L, Stigloher C, Richmond JE, Paoletti P \& Bessereau JL (2012) Positive modulation of a Cys-loop acetylcholine receptor by an auxiliary transmembrane subunit. Nat Neurosci 15, 1374-1381.

7. Sinha A, Eniyan K, Sinha S, Lynn AM \& Bajpai U (2015) Functional analysis of TPM domain containing Rv2345 of Mycobacterium tuberculosis identifies its phosphatase activity. Protein Expr Purif 111, 23-27.

This article is protected by copyright. All rights reserved. 
8. Stark JL, Copeland JC, Eletsky A, Somerville GA, Szyperski T \& Powers R (2014) Identification of low-molecular-weight compounds inhibiting growth of corynebacteria: potential lead compounds for antibiotics. ChemMedChem 9, 282-285.

9. D'Amico S, Sohier JS \& Feller G (2006) Kinetics and energetics of ligand binding determined by microcalorimetry: insights into active site mobility in a psychrophilic alphaamylase. J Mol Biol 358, 1296-1304.

10. Tsigos I, Velonia K, Smonou I \& Bouriotis V (1998) Purification and characterization of an alcohol dehydrogenase from the Antarctic psychrophile Moraxella sp. TAE123. Eur $J$ Biochem 254, 356-362.

11. Hsu F \& Mao Y (2015) The structure of phosphoinositide phosphatases: Insights into substrate specificity and catalysis. Biochim Biophys Acta 1851, 698-710.

12. Seifried A, Schultz J \& Gohla A (2013) Human HAD phosphatases: structure, mechanism, and roles in health and disease. FEBS $J$ 280, 549-571, doi: 10.1111/j.17424658.2012.08633.x.

13. Holm L \& Sander C (1998) Touring protein fold space with Dali/FSSP. Nucleic Acids Res 26, 316-319.

14. Kawabata T (2003) MATRAS: A program for protein 3D structure comparison. Nucleic Acids Res 31, 3367-3369.

15. Dougherty WG, Carrington JC, Cary SM \& Parks TD (1988) Biochemical and mutational analysis of a plant virus polyprotein cleavage site. EMBO J 7, 1281-1287.

16. Feller G \& Gerday C (2003) Psychrophilic enzymes: hot topics in cold adaptation. Nat Rev Microbiol 1, 200-208.

17. Huang H, Pandya C, Liu C, Al-Obaidi NF, Wang M, Zheng L, Toews Keating S, Aono M, Love JD, Evans B, et al. (2015) Panoramic view of a superfamily of phosphatases through substrate profiling. Proc Natl Acad Sci U S A 112, E1974-1983.

This article is protected by copyright. All rights reserved. 
18. Khachane AN, Timmis KN \& dos Santos VA (2005) Uracil content of 16S rRNA of thermophilic and psychrophilic prokaryotes correlates inversely with their optimal growth temperatures. Nucleic Acids Res 33, 4016-4022.

19. Russell NJ (1997) Psychrophilic bacteria--molecular adaptations of membrane lipids. Comp Biochem Physiol A Physiol 118, 489-493.

20. Feller G (2007) Life at low temperatures: is disorder the driving force? Extremophiles 11, 211-216.

21. Scheeff ED \& Bourne PE (2005) Structural evolution of the protein kinase-like superfamily. PLoS Comput Biol 1, e49.

22. Taylor SS \& Radzio-Andzelm E (1994) Three protein kinase structures define a common motif. Structure 2, 345-355.

23. Fagerbakke KM, Norland S \& Heldal M (1999) The inorganic ion content of native aquatic bacteria. Can J Microbiol 45, 304-311.

24. Heldal M, Norland S, Erichsen ES, Sandaa RA, Larsen A, Thingstad F \& Bratbak G (2012) Mg2+ as an indicator of nutritional status in marine bacteria. ISME J 6, 524-530.

25. Eibl H \& Lands WE (1969) A new, sensitive determination of phosphate. Anal Biochem 30, 51-57.

26. Delaglio F, Grzesiek S, Vuister GW, Zhu G, Pfeifer J \& Bax A (1995) NMRPipe: a multidimensional spectral processing system based on UNIX pipes. J Biomol NMR 6, 277293.

27. Johnson BA (2004) Using NMRView to visualize and analyze the NMR spectra of macromolecules. Methods Mol Biol 278, 313-352.

28. Hornak V, Abel R, Okur A, Strockbine B, Roitberg A \& Simmerling C (2006) Comparison of multiple Amber force fields and development of improved protein backbone parameters. Proteins 65, 712-725.

This article is protected by copyright. All rights reserved. 
29. Cerutti DS, Swope WC, Rice JE \& Case DA (2014) ff14ipq: A Self-Consistent Force Field for Condensed-Phase Simulations of Proteins. J Chem Theory Comput 10, 4515-4534.

30. Price DJ \& Brooks CL, 3rd (2004) A modified TIP3P water potential for simulation with Ewald summation. J Chem Phys 121, 10096-10103.

31. van Gunsteren WF \& Berendsen HJ (1984) Computer simulation as a tool for tracing the conformational differences between proteins in solution and in the crystalline state. $J \mathrm{Mol}$ Biol 176, 559-564.

32. Smith W \& Forester TR (1996) DL_POLY_2.0: a general-purpose parallel molecular dynamics simulation package. J Mol Graph 14, 136-141.

33. Darden TA \& Pedersen LG (1993) Molecular modeling: an experimental tool. Environ Health Perspect 101, 410-412.

34. Humphrey W, Dalke A \& Schulten K (1996) VMD: visual molecular dynamics. J Mol Graph 14, 33-38, 27-38.

This article is protected by copyright. All rights reserved. 


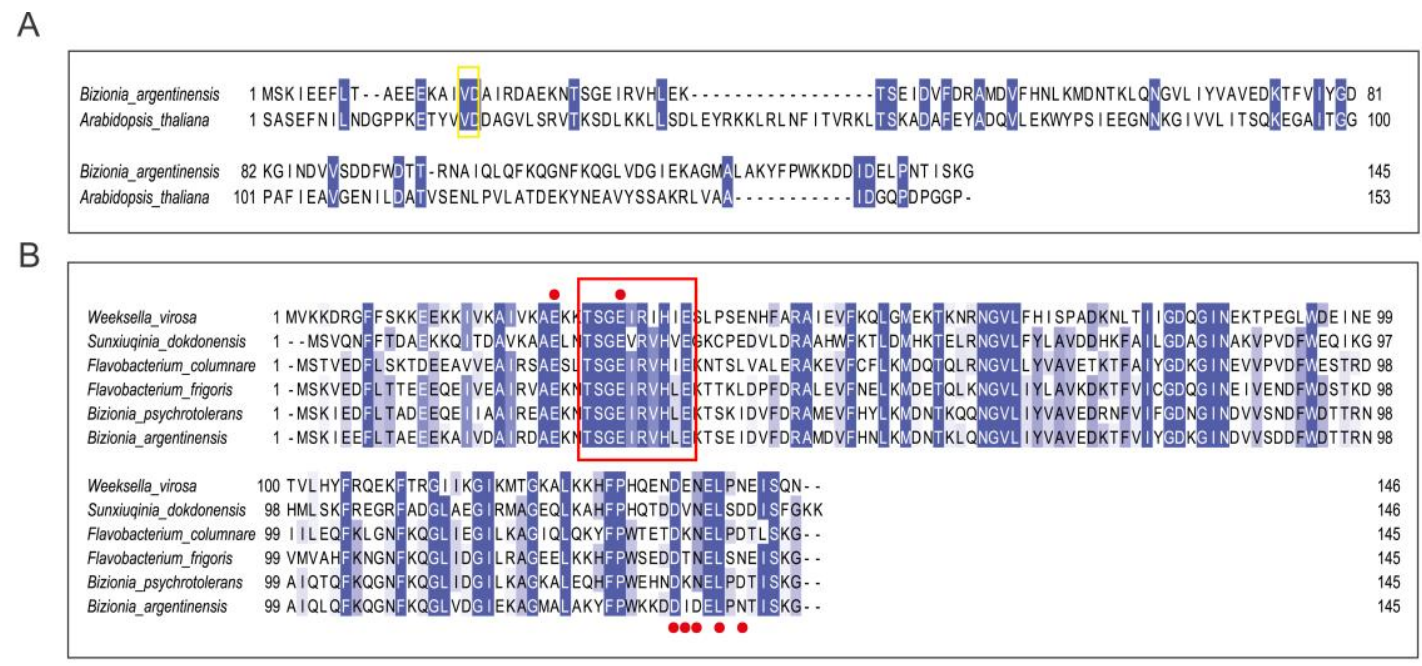

C

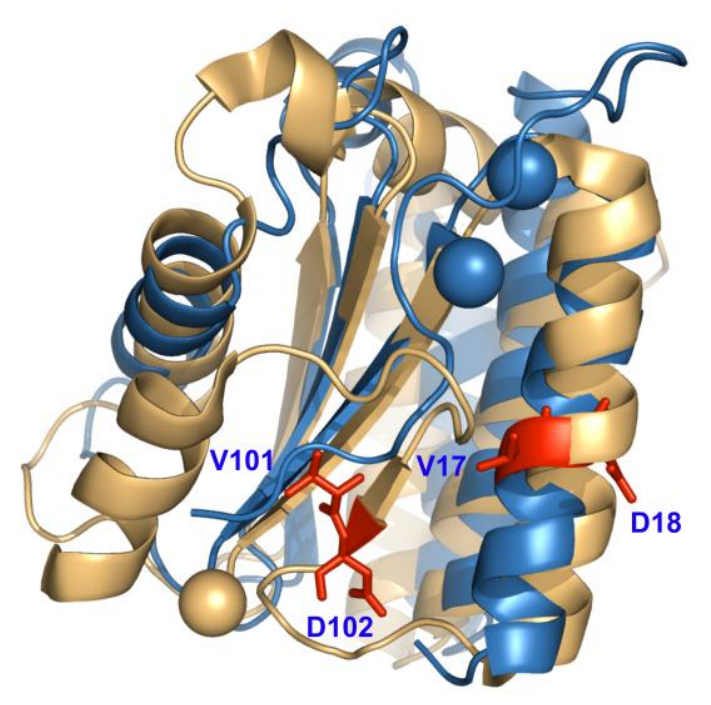

Figure 1: (A) Alignment of BA42 with the amino acid sequence of the TPM domain of AtTLP18.3 from A. thaliana generated by ClustalW (http://www.ebi.ac.uk/clustalW). Yellow box indicate conservation of the Val101 and Asp102 proposed to be involved in substrate binding in AtTLP18.3. Residues shaded in blue are strictly conserved. (B) Sequence alignment of BA42 and five homologs belonging to the phylum Bacteroidetes. Red dots indicate residues involved in metal coordination in the crystal structure of BA42. The conservation of the down loop and $\beta$-strand I residues is shown boxed in red. Residues 
shaded in blue are strictly conserved and those shaded in light blue are partially conserved. (C) Schematic superposition of crystal structures of BA42 (blue) and AtTLP18.3 (brown). The solid spheres represent the $\mathrm{Ca}^{2+}$ ions in both structures. The residues of the ligand binding site of AtTLP18.3 and the conserved aminoacids in BA42 are highlighted in red.

A
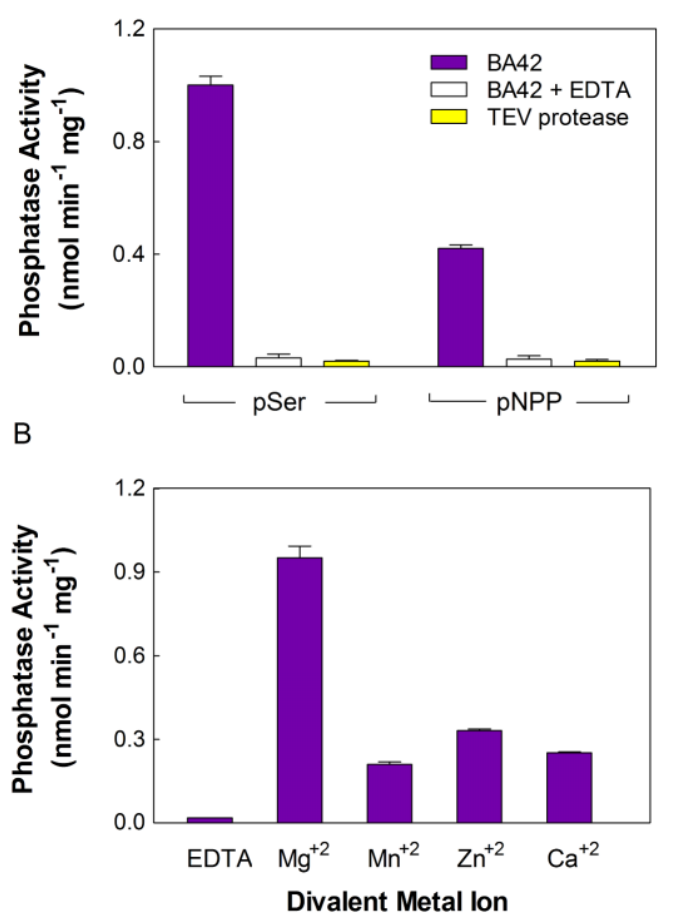

Figure 2: Phosphatase activity of BA42. A) The activity was assayed with the general substrates p-nitrophenyl phosphate (pNPP) and phosphoserine (pSer) by incubating samples of BA42 in $20 \mathrm{mM}$ Tris- $\mathrm{HCl}\left(\mathrm{pH} \mathrm{7.5)}\right.$ at $25^{\circ} \mathrm{C}$ in the presence or absence of EDTA. TEV protease was used as a control. B) Effect of divalent metal ions on the phosphatase activity. BA42 was treated with EDTA, extensively dialyzed to remove the EDTA, and finally tested its phosphatase activity in $25 \mathrm{mM}$ HEPES ( $\mathrm{pH} 7.0$ ) at $22^{\circ} \mathrm{C}$ and in the presence of several divalent metals. All experiments were performed in triplicate and results are expressed as mean \pm SEM.

This article is protected by copyright. All rights reserved. 


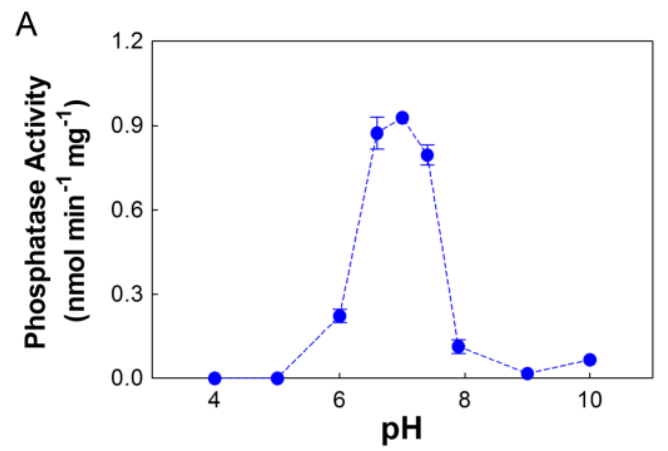

B
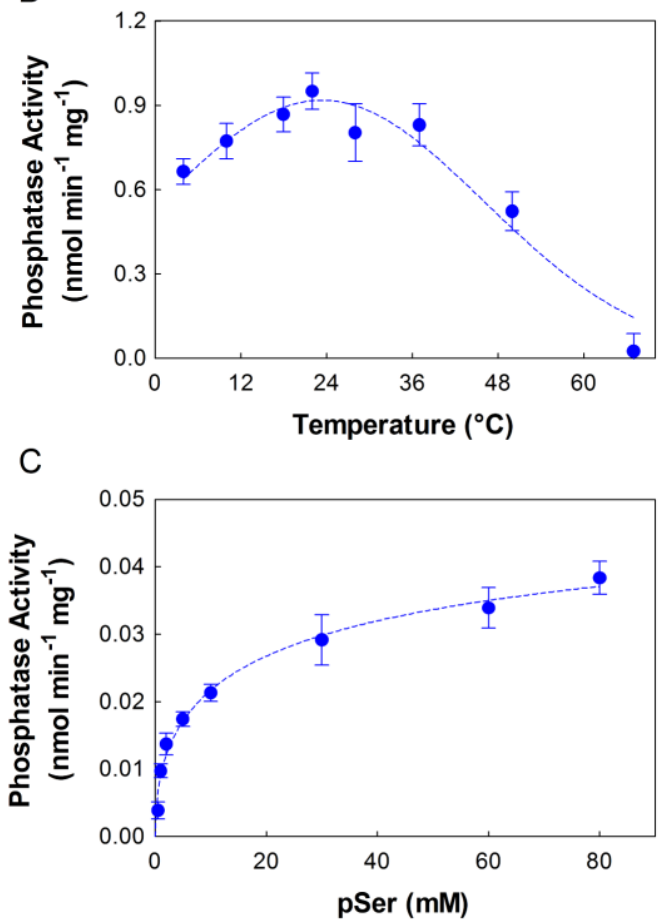

Figure 3: Biochemical characterization of the phosphatase activity of BA42. $\mathrm{Mg}^{2+}$-bound BA42 was incubated under different conditions with pSer and the Pi released was biochemically quantified. A) Influence of $\mathrm{pH}$ on phosphatase activity. The phosphatase activity was measured at different $\mathrm{pHs}$ at $22{ }^{\circ} \mathrm{C}$. The maximum activity was found around $\mathrm{pH}$ 7. B) Effect of temperature on enzyme activity. The phosphatase activity was measured at different temperatures in $25 \mathrm{mM}$ HEPES ( $\mathrm{pH}$ 7.0). The maximum activity was observed at 20 ${ }^{\circ} \mathrm{C}$. C) Enzymatic kinetics under optimal catalytic conditions. The phosphatase activity of $\mathrm{Mg}^{2+}$-bound BA42 was measured at increasing concentrations of substrate at $\mathrm{pH} 7$ and $20^{\circ} \mathrm{C}$. All experiments were performed in triplicate and results are expressed as mean \pm SEM.

This article is protected by copyright. All rights reserved. 
A

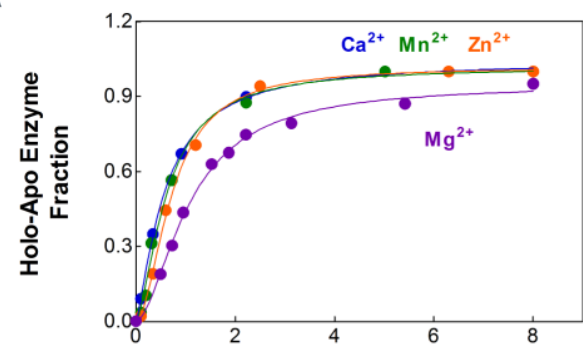

B

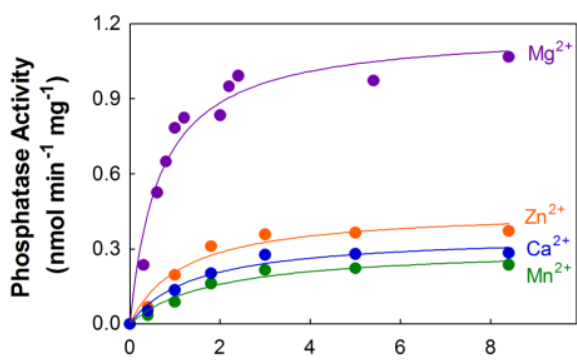

C

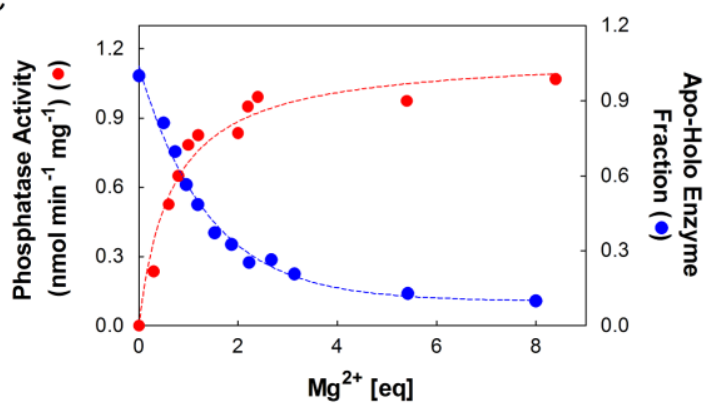

Figure 4: Relationship between the enzyme activity and the binding of divalent metals to BA42. The metal-free BA42 $(10 \mu \mathrm{M})$ was incubated in solutions containing $20 \mathrm{mM}$ Tris- $\mathrm{HCl}$, (pH 7), $20 \mathrm{mM}$ pSer and varying concentrations of different divalent metals. A) The metal binding was followed by monitoring the conformational change from metal-free to $\mathrm{Me}^{2+}$ bound BA42 by 1D ${ }^{1} \mathrm{H}$ NMR spectra. B) Phosphatase activity of $\mathrm{Me}^{2+}$-bound BA42 at different metal concentrations. C) Phosphatase activity and conformational change of metalfree BA42 as a function of $\mathrm{Mg}^{2+}$ concentration.

This article is protected by copyright. All rights reserved. 

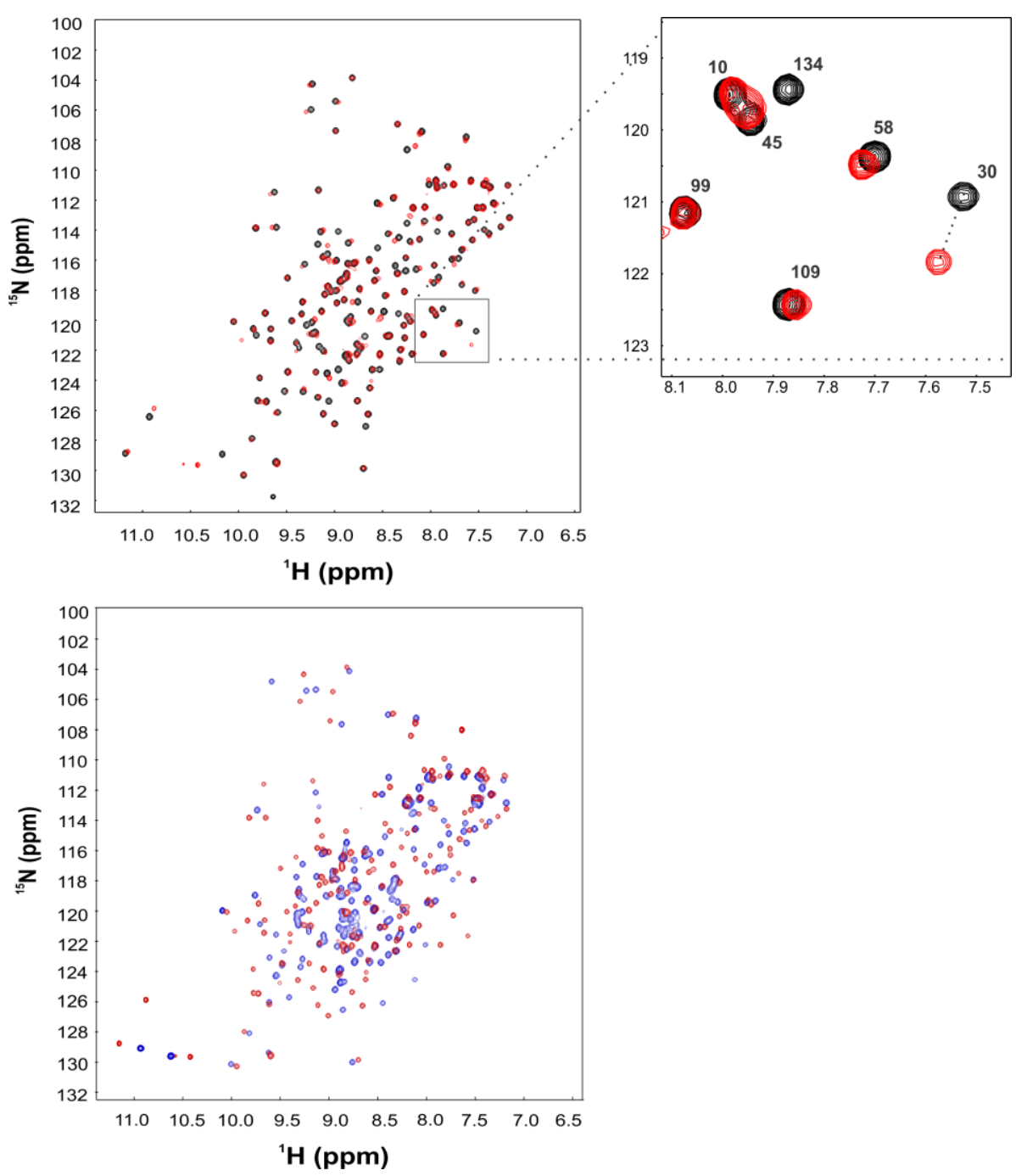

Figure 5: Changes in ${ }^{1} \mathrm{H}_{-}{ }^{15} \mathrm{~N}$ HSQC spectrum of BA42 induced by $\mathrm{Mg}^{2+}$ and $\mathrm{Ca}^{2+}$. Upper panel: The overlapping ${ }^{1} \mathrm{H}_{-}{ }^{15} \mathrm{~N}$ HSQC spectra of $\mathrm{Mg}^{2+}$-bound $\mathrm{BA} 42$ (red) and $\mathrm{Ca}^{2+}$-bound BA42 (black) is displayed. In the zoomed view, the variation of the amide signal for selected residues is indicated as example. The cross peak of residue 134 is not present in $\mathrm{Mg}^{2+}$-bound BA42 spectrum and there is a significant chemical shift perturbation of the amide signal of residue 30 between the two spectra. Lower panel: The overlapping ${ }^{1} \mathrm{H}_{-}{ }^{15} \mathrm{~N}$ HSQC spectra of $\mathrm{Mg}^{2+}$-bound BA42 (red) and BA42- Apo (blue) is displayed.

This article is protected by copyright. All rights reserved. 
A

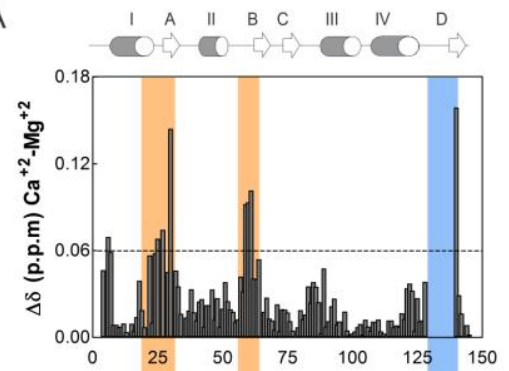

B

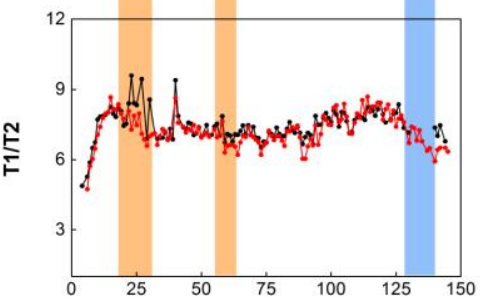

C

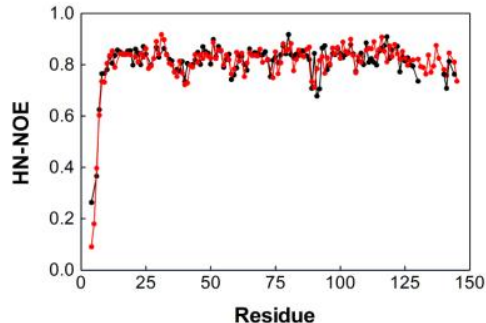

D

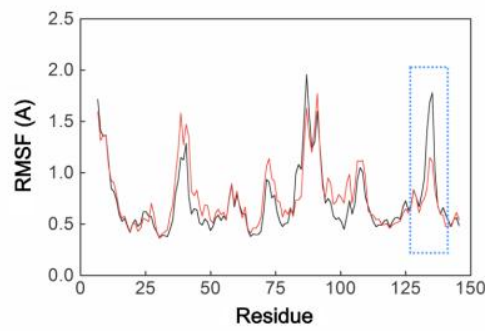

$E$

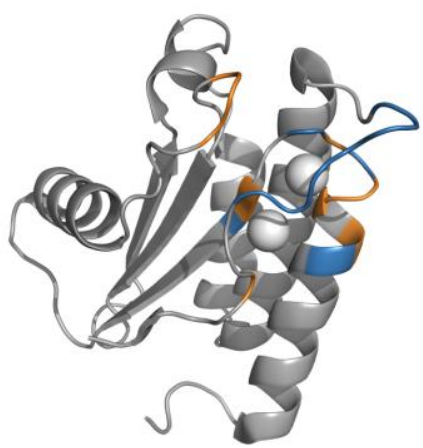

$\mathrm{F}$

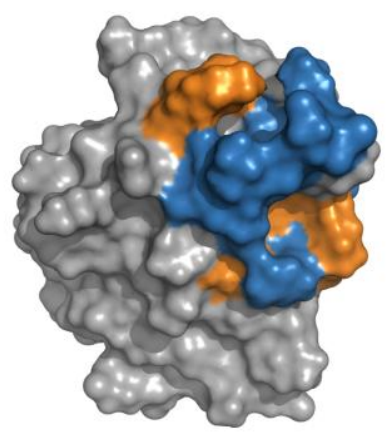

G

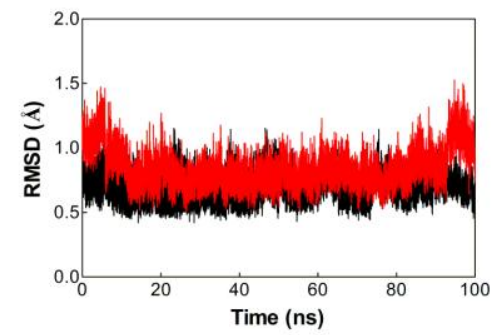

This article is protected by copyright. All rights reserved. 
Figure 6: $\mathrm{HN}$ chemical shift perturbation and dynamics of $\mathrm{Mg}^{2+}$-bound and $\mathrm{Ca}^{2+}$-bound BA42. A) HN chemical shift perturbation. Overhead, the secondary structure of BA42; the $\alpha-$ helices are represented by white arrows and $\beta$-sheets by grey cylinders. The $\Delta \delta$ threshold value was set to 0.06. B) Comparison of ${ }^{15} \mathrm{~N} \mathrm{T1/T2}$ ratios of $\mathrm{Mg}^{2+}$-bound (black) and $\mathrm{Ca}^{2+}$ bound (red) BA42. The bars are drawn in order to easily compare residues between plots A, B and the secondary structure of BA42. The light orange bars highlight residues with highest chemical shift perturbation values. The light blue bar highlights the missing residues in the ${ }^{1} \mathrm{H}_{-}{ }^{15} \mathrm{~N}$ HSQC spectra of $\mathrm{Mg}^{2+}$-bound BA42. C) ${ }^{1} \mathrm{H}^{-}{ }^{15} \mathrm{~N}$ heteronuclear NOE of BA42. H-N NOEs were measured for the $\mathrm{Ca}^{2+}$-bound BA42 (red) and $\mathrm{Mg}^{2+}$-bound BA42 (black). D) MD simulations of metal-bound BA42. RMSF calculations for $\mathrm{Ca}^{2+}$-bound BA42 (red) and $\mathrm{Mg}^{2+}$ bound BA42 (black) are shown. E) Ribbon view of metal-bound structure evidencing the residues with highest chemical shift perturbation values (in orange) and the missing residues in the ${ }^{1} \mathrm{H}^{-15} \mathrm{~N}$ HSQC spectra of $\mathrm{Mg}^{2+}$-bound BA42 (in blue). F) Surface plot of the structure displayed in D). G) RMSD calculations for $\mathrm{Ca}^{2+}$-bound (black) and $\mathrm{Mg}^{2+}$-bound BA42 (red).

This article is protected by copyright. All rights reserved. 

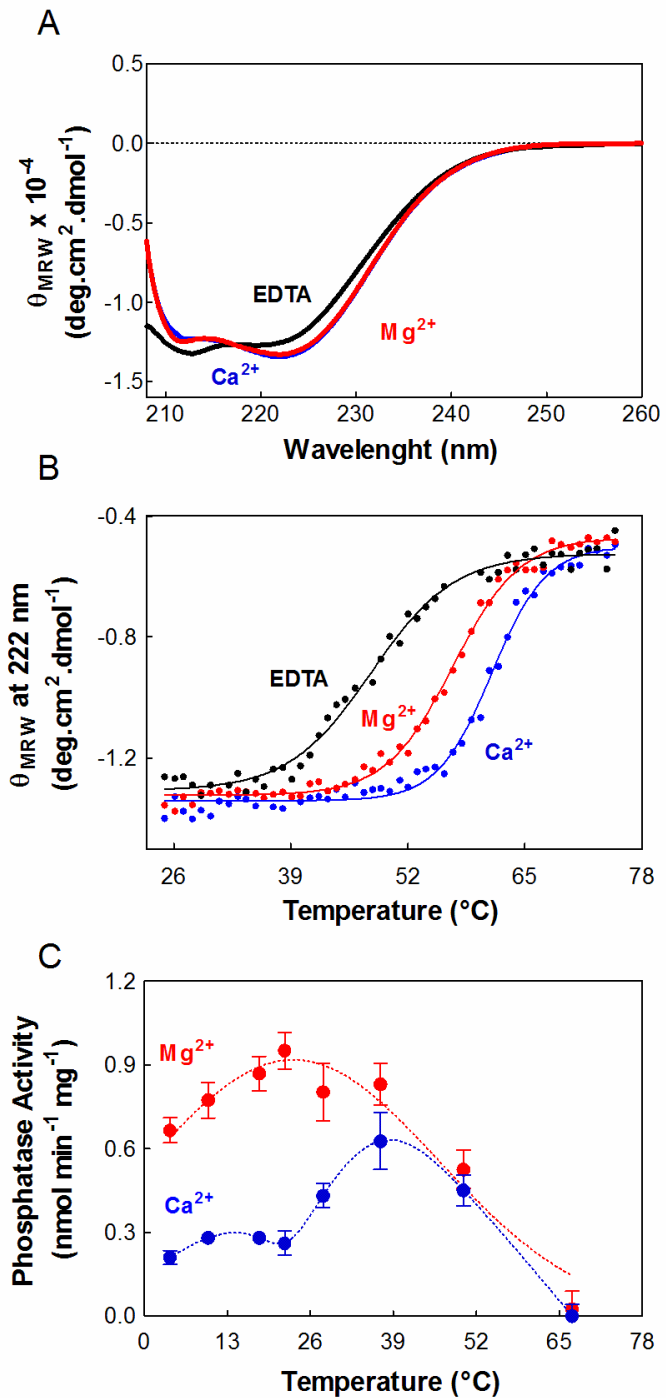

Figure 7: A) Circular dichroism spectra of BA42. The CD spectra of metal-free (black line), $\mathrm{Mg}^{2+}$-bound (red line) and $\mathrm{Ca}^{2+}$-bound BA4 (blue line) were recorded at $25^{\circ} \mathrm{C}$. B) Thermal unfolding process of BA42. Metal-free (black line), $\mathrm{Mg}^{2+}$-bound (red line) and $\mathrm{Ca}^{2+}$-bound BA4 (blue line) were incubated at different temperatures from 25 to $75{ }^{\circ} \mathrm{C}$ and the molar ellipticity at $222 \mathrm{~nm}$ was recorded at intervals of $1{ }^{\circ} \mathrm{C}$. C) Effect of temperature on enzyme activity of BA42. The phosphatase activity was measured at different temperatures in $25 \mathrm{mM}$ HEPES (pH 7.0) and in the presence of $1 \mathrm{mM} \mathrm{CaCl}_{2}$ (blue dots) or $1 \mathrm{mM} \mathrm{MgCl}_{2}$ (red dots). The activity assays were performed in triplicate and the results are expressed as mean \pm SEM. 
A

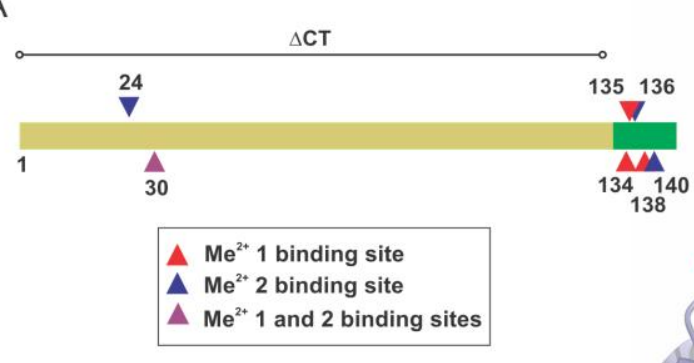

C
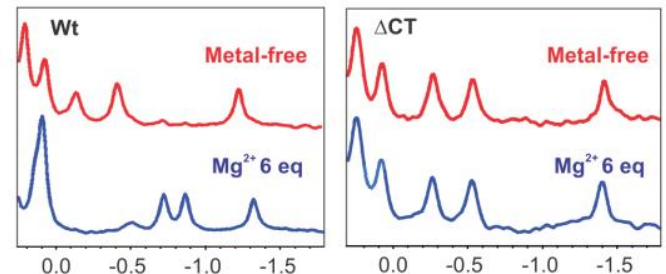

E

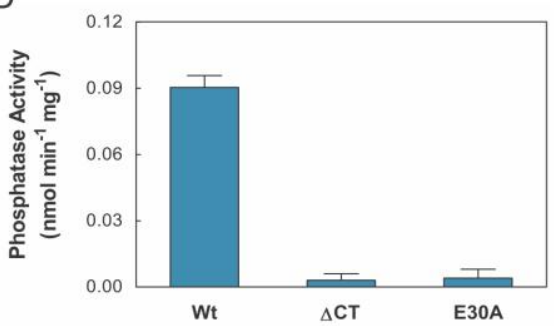

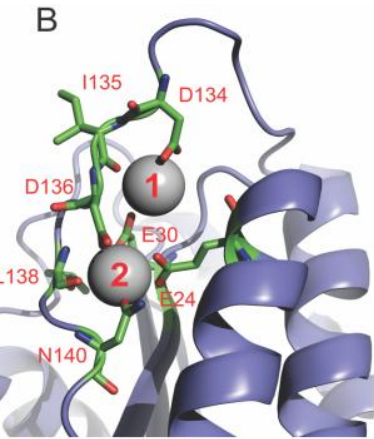
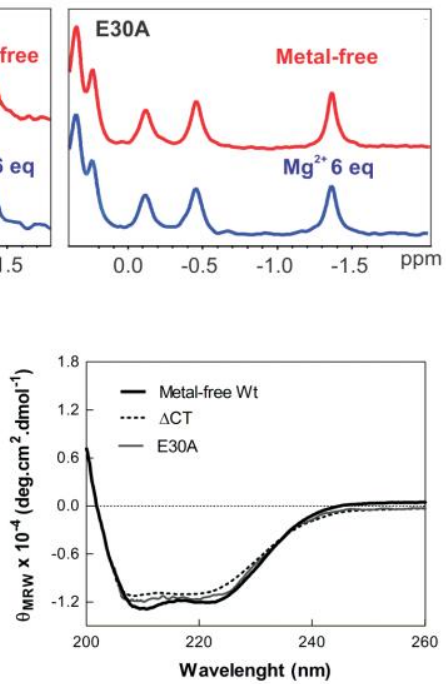

Figure 8: Analysis of BA42 mutants. A) Schematic representation of the primary sequence of BA42 where residues involved in the metal binding site and the C-terminal region are indicated. The mutant BA42- $\triangle \mathrm{CT}$ is comprised of residues 1-130 (yellow rectangle) and lacks the C-terminal region (green rectangle). The red triangles indicate the residues involved in metal 1 binding site and blue triangles highlight those interacting with metal 2 . The purple triangle indicates the Glutamic acid 30 that interacts with both metals. B) A detail of the structure of BA42 showing the metal-binding region. The solid spheres represent the $\mathrm{Ca}^{2+}$ ions (arbitrary labeled as 1 and 2) and the residues of the metals binding site are highlighted in red. C) $1 \mathrm{D}{ }^{1} \mathrm{H}-\mathrm{NMR}$ spectra of BA42 variants in the range of 0.25 to $-1.75 \mathrm{ppm}$. The spectra were recorded for the metal-free proteins and in the presence of 6 equivalents of $\mathrm{Mg}^{2+}$. (D) The phosphatase activity of $\mathrm{Wt}$ BA42 and mutants proteins was assayed in the presence of 6 equivalents of $\mathrm{Mg}^{2+}$. E) The CD spectra of metal-free Wt (black line), BA42$\Delta \mathrm{CT}$ (dashed line) and BA42-E30A (grey line) were recorded at $25^{\circ} \mathrm{C}$. 


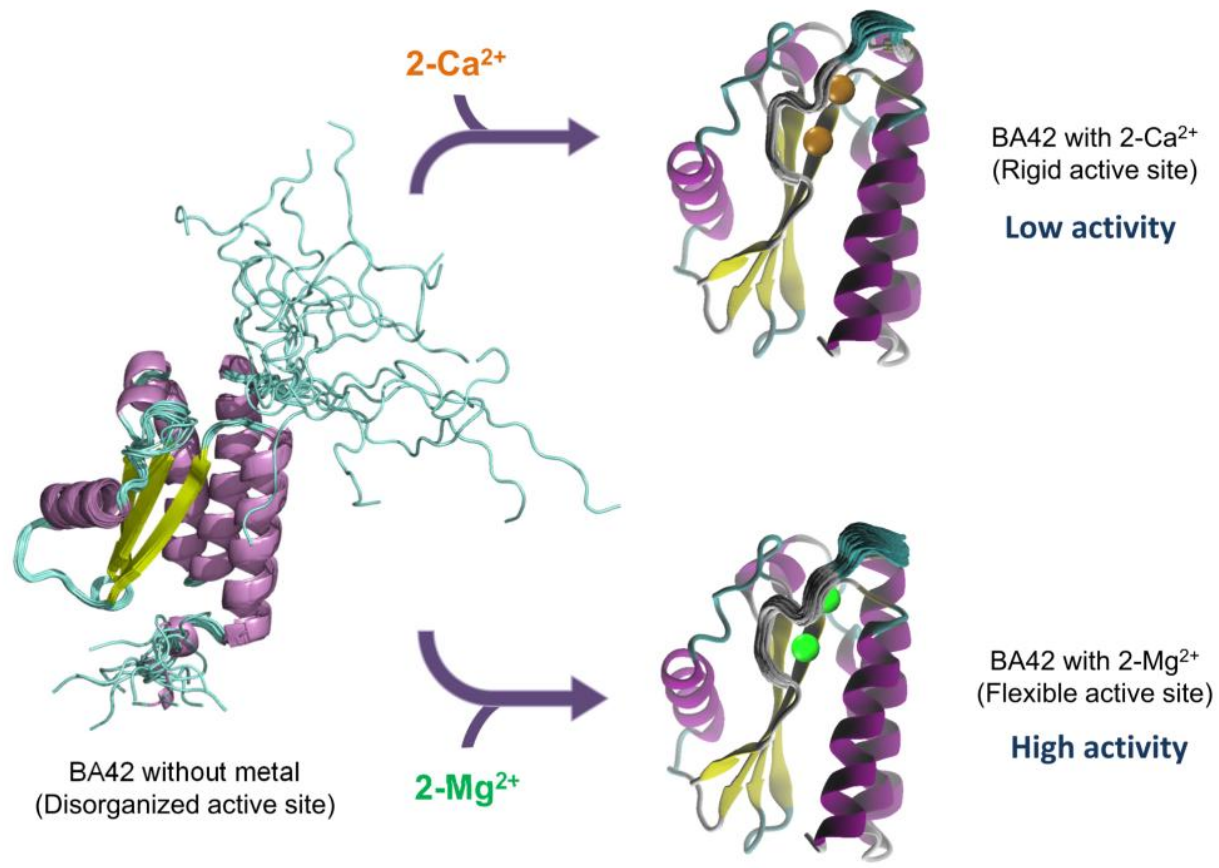

Figure 9: A schematic representation of the metal-dependent behavior of the catalytic region of BA42. The figure illustrates the postulated mechanism of phosphatase activity modulation by varying the flexibility of the active site. In the absence of divalent metal ions the Cterminal region of BA42 is extremely disordered and the active site is not formed. In the presence of $\mathrm{Ca}^{2+}$ the active site acquires a rigid configuration and the activity is low. The binding of $\mathrm{Mg}^{2+}$ induces an increment of the flexibility of the active site, in comparison with the protein bound to $\mathrm{Ca}^{2+}$, and the protein activity is highly increased.

This article is protected by copyright. All rights reserved. 